\title{
Hacer teología en nuestro tiempo y en nuestro lugar ${ }^{*}$
}

\author{
Jon Sobrino, \\ Centro de Reflexión Teológica, \\ San Salvador
}

Me han invitado a abrir este Congreso Continental de Teología Latinoamericana. Su finalidad consiste en "discernir los nuevos desafíos de una época marcada por profundas transformaciones y preguntarse por las futuras tareas desde un nuevo contexto cultural, social, político, económico, religioso y eclesial, globalizado y excluyente".

El intento me parece bueno y necesario, pero presentar este congreso con esta finalidad me sobrepasa. Pedí a los organizadores que me excusasen, pero insistieron. Acepté, y haré algunas reflexiones que puedan ayudar al trabajo de estos días.

Quiero añadir una convicción. A estar aquí, pienso que nos mueve algo que va más allá de lo profesional. Cada uno y cada una podrá decírselo a su manera. Creo que es la decisión a trabajar por el Reino de Dios en este continente latinoamericano. En palabras de Ignacio Ellacuría, la decisión a "empujar, sin desmayar, el carro de la historia". A través de Miqueas, Dios nos pide que lo empujemos "practicando la justicia, amando con ternura y caminando humildemente con Dios". Espero que el congreso ayude.

Me toca ahora ambientarlo, y lo haré en dos partes. En el cuerpo de la ponencia, tocaré el tema de "la Iglesia de los pobres". Es de gran importancia sistemática y actual. Además, nos lleva a recodar y repensar lo que queremos celebrar estos días: el Concilio Vaticano II, Juan XXIII y el pacto de las catacumbas, más Medellín, los padres de la Iglesia latinoamericana, monseñor Romero y la teología que inauguró Gustavo Gutiérrez.

* Ponencia dada el 7 de octubre de 2012 en la universidad Unisinos, en Brasil. 
Antes, sin embargo, voy a hacer tres reflexiones de tipo personal. La primera es explicar, en sentido preciso, por qué me siento un poco abrumado ante más de 700 personas que han venido de toda América Latina y el Caribe, con tradiciones y expectativas diversas. Yo solo puedo hablar desde una historia y una edad a las que hoy se les escapan muchas de las realidades actuales. La segunda es qué entiendo por "celebrar" acontecimientos del pasado. Y la tercera es qué significado puede tener "volver al pasado", siendo así que el congreso insiste en las novedades del presente, y en qué sentido ese "volver" puede ser una necesidad.

\section{Tres reflexiones previas}

\subsection{El Salvador: horror y generosidad}

Vengo de un país pequeño, de 22,000 kilómetros cuadrados y 6 millones de habitantes, más otros 3 millones que han tenido que salir de él para poder vivir. Es cierto que existe una importante tradición teológica, y periódicamente llegan teólogos de fuera. Pero El Salvador no es, como puede serlo Brasil, una encrucijada habitual de temas teológicos: nuevos paradigmas, sujetos emergentes, religiones indígenas, género, movimientos agnósticos de envergadura, ecosistemas, madre tierra... Tampoco llegan a la opinión pública, ni se discuten al interior de la Iglesia, asuntos de Iglesia que exigen solución urgente: pérdida de identidad local promovida por la imposición universal desde la lejana Roma, posibilidad de ordenar viri probati, negación de la ordenación de mujeres considerada como "verdad definitiva"... Y una especie de dogma de intocabilidad con respecto a la jerarquía, que subsiste más allá y en contra de la fraternidad dentro del pueblo de Dios.

Algo de esta problemática nos llega, por supuesto, pero en la región centroamericana, además de lo dicho, la realidad cotidiana trae consigo urgencias impostergables a las que hay que atender prioritariamente. No excusan a la teología, por supuesto, de abordar temas nuevos, pero menos la excusan de no abordar temas urgentes y clamorosos. Digámoslo claramente: en lugares como El Salvador estamos ante el horror de la muerte. Y también hemos estado -y estamos todavía - ante la generosidad de dar vida dando la vida, en la realidad o en la memoria viva.

\section{a. Horror masivo: los 20 años en El Salvador desde los Acuerdos de Paz}

Los homicidios, las extorsiones y las desapariciones forzadas de personas - en un entorno nacional donde abundan además otros delitos- han mantenido a nuestra sociedad postrada ante la inseguridad y la violencia durante dos décadas después de la guerra. No quedaron atrás al terminar el conflicto armado, dentro del cual fueron prácticas sistemáticas con motivación política; al contrario, las legitimaron sus autores y protectores con la amnistía. Al final de esos veinte años, era justo y necesario que ya reinara en el país la paz 
social; sobre todo, para que la gozaran las mayorías populares, que fueron las más sufridas por la grave violación de sus derechos humanos antes de la guerra y durante la misma.

Sin embargo, a lo largo de ese período, la realidad ha sido otra: más de cien mil asesinatos cometidos principalmente con armas de fuego, quién sabe cuántas desapariciones y millonarias sumas de dinero que la gente ha pagado a la delincuencia - la famosa "renta" - y así evadir la muerte. Hubo años en que las víctimas fatales superaron las siete mil; otros en los que giraron alrededor de las tres mil. En medio de esos vaivenes de una estadística trágica, nuestro país estuvo ubicado siempre entre los más peligrosos del mundo. El año pasado cerró con cuatro mil 354 homicidios intencionales; en 2010 también rebasaron los cuatro mil.

En aras de eso, los pleitos entre los poderes políticos, económicos, mediáticos y otros deberían pasar a un segundo plano. La sangre, el hambre y la impunidad son los obstáculos esenciales para que en El Salvador - tras veinte años sin guerra - se mantenga el "mal común" en beneficio de minorías privilegiadas antiguas y recientes. Las mayorías populares, de donde sale la gente que busca escapar de las infamias sociales antes citadas, deben pasarles la factura mediante su organización para la defensa decidida, creativa y firme de los derechos que les son negados. ${ }^{1}$

El texto es local, aunque remite a amplias zonas de Mesoamérica. Pero es necesario tenerlo presente para saber estar ante la realidad y para hacer teología. Metz se preguntaba “cómo hacer teología después de Auschwitz". En Centroamérica seguimos en nuestros propios Auschwitz. En ellos hay que hacer teología, abierta a todos los temas teológicos, ciertamente. Pero el horror y la generosidad - de la que en seguida hablaremos - no pueden no tener un lugar central en la teología. Desentenderse de ello, porque en definitiva "no dice nada nuevo", sonaría a blasfemia.

$\mathrm{Y}$ al homicidio hay que añadir la emigración, la indignidad, el desamparo... $\mathrm{Y}$ el tipo de horror del que solo vamos a mencionar el nombre: el hambre. Para Casaldáliga, tiene importancia suprema, y le otorga estatus teologal: "Todo es relativo menos Dios y el hambre". Las grandes mayorías sufren hambre y se aferran a Dios. Lo que buscan con mayor urgencia sigue siendo la vida, y la esperanza que les permita seguir viviendo cuando aquella está en peligro. Por eso miran "a lo alto". Dios es lo absoluto. El hambre es lo co-absoluto.

1. B. Cuéllar, "El país sigue doliente y dolido", Carta a las iglesias, agosto 2012, 2s. Reflexiones similares se pueden hacer sobre Honduras, Guatemala y zonas de México, que son corredor de migración, narcotráfico y homicidios. 


\section{b. Veinte años de mártires: un torrente de generosidad}

En los pequeños países a los que he aludido, se ha dado un hecho descomunal y sin precedentes: infinidad de mártires. Un sentido común que no se haya aburguesado o corrompido, y ciertamente el sensus fidei, exigen mantener viva la realidad de esos martirios. Son cuestionantes y acusantes, pero son sobre todo memoria evangélica y escandalosamente bienaventurada.

No es fácil verlo así. En Roma, al parecer, todavía no saben qué hacer con monseñor Romero y con docenas de sacerdotes y religiosas, más centenares o miles de laicos. Y tampoco es fácil poner en palabra precisa el significado más profundo de los mártires de hoy. Pienso que son "mártires de la verdad y de la justicia", como Jesús. Pero si se quiere afinar el concepto, surgen preguntas semejantes a las que se hacen los Evangelios ante el crucificado. ¿Muere Jesús solo y abandonado en un contexto apocalíptico (Marcos)? ¿Muere como el modelo del justo mártir (Lucas)? ¿Muere majestuosamente, "todo está cumplido", "Tú eres mi Dios" (Juan) ${ }^{2}$ ? Y nada digamos si se buscan referentes seculares: ¿muere Jesús, estoicamente como Sócrates, crucificado como Espartaco el libertador de esclavos, o como el mártir rojo de Bloch que va cantando entusiastamente a la muerte? Menciono esto para que la teología se ocupe de los martirios en nuestra época con mayor profundidad e interés que el habitual.

Entre nosotros existen, además, mayorías, pueblos, que, lenta o violentamente, son dados muerte. Ellacuría los llamó "el pueblo crucificado", y dijo de él que es siempre "el" signo de los tiempos. En su máxima generalidad, lo definió como

aquella colectividad que, siendo la mayoría de la humanidad, debe su situación de crucifixión a un ordenamiento social promovido y sostenido por una minoría que ejerce su dominio en función de un conjunto de factores, los cuales, como tal conjunto y dada su concreta efectividad histórica, deben estimarse como pecado. ${ }^{3}$

Teológicamente, el pueblo crucificado es la presencia en la historia del siervo sufriente, que trae salvación. De igual forma, monseñor Romero lo llamó "el divino traspasado". Ha pasado el tiempo, pero dudo que el presente haya hecho obsoletas las palabras de Ellacuría, o inútil su reflexión teológica, junto con la de monseñor.

Siempre hay que historizar los diversos tipos de mártires individuales - los llamamos "jesuánicos"-, y las diversas formas que toma el pueblo crucificado. Hoy hay que tener muy especialmente presentes a los niños que, inocente e

2. Más en detalle, véase J. Sobrino, Jesucristo liberador. Lectura histórico-teológica de Jesús de Nazaret, San Salvador, 1991, pp. 395-399.

3. I. Ellacuría, "El pueblo crucificado, ensayo de soteriología histórica", Revista Latinoamericana de Teología 18 (1989), p. 318. 
indefensamente, en número muy elevado, mueren de hambre o de enfermedades relacionadas con el hambre. "Mueren asesinados", dice desde hace años Jean Ziegler, comisionado de la FAO, pues el hambre es técnicamente eliminable. Esos niños son hoy, en forma real, los que en el relato de Mateo aparecen en forma legendaria: los niños inocentes asesinados por Herodes.

No hay que caer en masoquismo, pero menos en liviandad. Y para ello es también necesario captar, sentir incluso, qué han sido y qué son los mártires y sus martirios. Podrá haber discusión teórica necesaria - en la que hemos participado- sobre el concepto de martirio. Pero solo con esa discusión no llegamos a "hacernos cargo de la realidad martirial", primer paso del proceso de inteligir, que decía Ellacuría. Solo con ella, menos aún, "nos encargamos de la causa de los mártires", luchar contra el antirreino y propiciar el reino. Ciertamente, no "cargamos con el peso del martirio". Y entonces los mártires tampoco "cargan con nosotros". No se nos aparecen como gracia y salvación.

Con excepciones en las sociedades de abundancia, aun las sociológicamente todavía cristianas, poco o nada les interesan los abundantes martirios y pueblos crucificados a lo largo y ancho del planeta. Están ciegos. No los ven ni los sienten como el siervo doliente y redentor.

\section{c. La importancia de los mártires para la teología}

Me he detenido en el tema de los mártires para explicar por qué en El Salvador podemos estar no tan volcados hacia otras novedades teológicas. Pero aprovecho la ocasión para afirmar que el martirio también puede iluminar, en positivo, varios temas de la teología.

(1) Buena y necesaria es la opción por los pobres, pero el martirio va más allá de ella. Es bueno recordarlo, pues en las iglesias, también entre las jerarquías, sí se suele hablar y escribir con cierta frecuencia sobre la opción por los pobres y su necesidad. Pero poco se habla con seriedad de los mártires. En definitiva, parece que no sabemos qué hacer con ellos, siendo ellos quienes más profundamente han optado por los pobres y quienes mejor reproducen la historia de Jesús de Nazaret. Es cierto que en la opción por los pobres puede ya haber elementos de un "martirio incruento". Pero ninguna opción puede hacer olvidar los innumerables martirios reales, crueles e ignominiosos.

(2) En el capítulo sobre la opción por los pobres, n. 1142, y en relación a ellos, Puebla hizo dos afirmaciones teologales de suma importancia. (a) "Por el mero hecho de ser pobres, sea cual fuere su realidad personal o moral", Dios se vuelca hacia ellos. Es la gratuidad teologal primordial. (b) Ese volcarse es descrito en dos dimensiones. La segunda es que Dios los ama, los cuida, los salva. Pero antes, el texto dice que "Dios toma su defensa". Aquí, optar tiene un significado muy específico: defender a los pobres de sus enemigos. Tomar la defensa implica, 
entonces, por necesidad enfrentase con los enemigos de los pobres. Estos no suelen reaccionar normalmente contra quienes meramente ayudan a los pobres, pero sí reaccionan contra quienes los defienden. Se convierten en amenaza para los ricos, y estos buscan eliminarlos.

"Se mata a quien estorba", decía lapidariamente monseñor Romero. Y esa es la lógica histórica del martirio en América Latina, cuya ausencia hacía notar Comblin al analizar la cristología de Aparecida. En el texto, Jesús anuncia buenas noticias a unos, pero no se dice que anuncia malas noticias a otros, ni que estos reaccionan para eliminar a Jesús. Algo parecido ocurre en el tratamiento de los mártires latinoamericanos. Se dice que son generosos en la entrega, pero no se dice que por defender a los pobres les sobreviene la persecución y el martirio. En el análisis de la actuación de Jesús y de nuestros mártires, falta el conflicto que lleva a ser dados muerte.

(3) En varias regiones del continente latinoamericano, los mártires han sido innumerables, tanto en su versión jesuánica, hombres y mujeres, campesinos y estudiantes, religiosas, sacerdotes, obispos, como en su versión de miembros del pueblo crucificado. En número y en la variedad de las causas del martirio (denunciar, desenmascarar, exigir a los que oprimen al pobre lo que se puede hacer con palabra explícita, o con la fuerza de la misma existencia oprimida), no tiene comparación con lo que ocurre en otros lugares. El miedo a las reacciones de los poderosos, coincidente con la prudencia de algunos jerarcas, llevó a veces a silenciar los hechos y hacer desaparecer a los mártires, con pérdida fundamental de credibilidad para las iglesias. Pero en muchos lugares ocurrió lo contrario: los mártires han marcado de forma importante el quehacer eclesial y el teológico. Y no creo que ninguna otra realidad histórica pueda sustituirlos para captar a cabalidad a Jesús de Nazaret, animarse a su seguimiento y encaminarse a la fe en el Cristo.

(4) No se hablaría de forma adecuada de los mártires si, aun con buena voluntad, se remitiese su realidad a cosa del pasado: de los mártires hay que "hacer memoria". Son "memoria subversiva", de la que habla Metz, para que lo nuevo sea humanizador, no acabe simplemente en moda o se convierta en algo positivamente deshumanizante. Son "memoria histórica", tan promovida por las ciencias sociales, para saber de qué horrores venimos, en la sociedad y en la Iglesia, qué tenemos que reparar, a quién tenemos que juzgar, con justicia y sin amnistías encubridoras, a quién debemos estar dispuestos a perdonar, a qué personas y pueblos debemos consolar. Y son "memoria cristiana". Mantienen presente en la realidad, no solo en la liturgia, la cena del Señor y la Pascua de Jesús.

Y nunca hay que olvidar que tanta realidad de mártires, de pueblos crucificados en Centroamérica, de pueblos indígenas (los de Leonidas Proaño y don Samuel Ruiz), de pobreza invisible (en Haití), de machismo depravado y homicida (zonas de México) han sido muy reales y muy cercanos a nuestra generación. $\mathrm{Y}$ en buena medida todavía persisten. 
Para terminar esta reflexión, quiero decir con sencillez algo que me ha venido a la mente con alguna frecuencia. Cuentan que el Apóstol Juan, ya anciano, solía repetir que el mensaje del Señor es "que se amen unos a otros", y que sus discípulos comentaban: "Siempre está diciendo lo mismo". Dicho ahora en lenguaje jocoso, los teólogos que insisten una y otra vez en los mártires y descuidan otras realidades novedosas, quizás podrán escuchar lo que escribió Cervantes sobre don Quijote: "La lectura de tantos libros de caballería le había sorbido el seso y le hizo perder el juicio". Volviendo al lenguaje serio, en teología no debemos desentendernos de realidades novedosas por un exceso de concentración en los mártires. Pero tampoco hay que encumbrar las novedades de tal modo que el amor y la entrega de los mártires queden relegados a ser recuerdo del pasado.

\subsection{Qué celebramos hoy y qué hacemos si en verdad celebramos}

El congreso también está pensado como celebración de los 50 años del inicio del Vaticano II y de los 40 años de la publicación del libro de Gustavo Gutiérrez Teología de la liberación. Organizar un congreso con referentes cronológicos importantes es normal, pero no debiera serlo de tal manera que se caiga en mera sacralización de la cronología. Pienso que celebrar acontecimientos en el tiempo no es simplemente rememorar "hitos" ni solo mostrar admiración por ciertos "textos", sino mantener o recuperar el impacto de "irrupciones" históricas y dejarse llevar por "los impulsos" históricos que aquellos acontecimientos y sus textos generaron. Si no ocurriera algo de esto, pienso que no habría celebración. Para explicar lo que quiero decir, permítanme recordar qué fue para mí el Vaticano II en 1965, y después Medellín, Gustavo Gutiérrez... En otras palabras, me pregunto qué puedo celebrar y qué no. Por qué celebro y no simplemente recuerdo esos acontecimientos.

En los años de 1966 a 1974, estudiaba teología en Sankt Georgen, Frankfurt. Del concilio tuve noticias fragmentarias y poco significativas por lo que toca a su impacto histórico y social. De Medellín y del libro de Gustavo Gutiérrez solo llegué a tener conocimiento y a interesarme en 1974, en mi segunda y definitiva llegada a El Salvador. A diferencia de muchos de mi generación, era ignorante de lo que estaba ocurriendo, y obviamente no fui ningún apasionado. Después, todo cambió. Más que el conocimiento sobre qué acontecimientos ocurrieron y qué textos se publicaron, fue la realidad salvadoreña con la que empecé a toparme la que hizo que se operase un cambio. En mi experiencia, aunque no viví inserto, la realidad de los pobres surgió como en un opthe. Y aparecía como la realidad por antonomasia.

Y fue también, y en mi caso sobre todo, la realidad del nuevo modo de vida y trabajo de los compañeros, la mayoría jesuitas, en la universidad, colegios, parroquias, con campesinos en el campo. Su trabajo tenía una novedad radical: era entrega a los pobres. Eso es lo que me ayudó a comprender y valorar los acontecimientos que habían tenido lugar: Medellín, teología de la liberación — por 
implicación, también el Vaticano II-, y a agradecer todo ello muy sinceramente. Eso me ayudó a leer los nuevos textos, de obispos y de teólogos; a interpretar sus contenidos y sobre todo a comprenderlos como expresión, en concepto, de impulsos reales que movían a cambiar realidades, sufrirlas y agradecerlas. Es decir, el concilio y Medellín no eran solo textos ni solo acontecimientos para la razón, sin impulsos de realidad. Me llegó e impactó el Medellín hecho realidad, no un Medellín solo pensado, escrito y publicado. Digamos lo mismo sobre el Vaticano II, que quedaba más distante. Ciertamente, de los mártires, que los teníamos al lado. Y de forma análoga, también de los textos de teólogos.

Hace poco escribí en Concilium cómo pocos años después todo ello fraguó en forma de realidad.

Me topé con el cristianismo en Aguilares, a 30 kilómetros de San Salvador, el 12 de marzo de 1977. El padre Rutilio Grande fue asesinado con dos campesinos. Ese día, y en lo que ocurrió inmediatamente después, irrumpió un cristianismo que yo nunca había vivido ni sospechado. Se habían roto las reglas no ya del bien, sino las del mal, aunque la crueldad contra los pobres había comenzado antes. Pero en Rutilio y en monseñor Romero, convertido desde ese día en defensor ex officio del pobre, también Jesús de Nazaret, conocido y estudiado durante años, se dejaba ver opthe. E irrumpió un cuerpo eclesial con la conversión al pobre, la locura de las bienaventuranzas y el amor mayor, un cuerpo unido como nunca y decidido a seguir. Muchos oraban al Padre celestial. Se palpaba la convicción, el compromiso y el orgullo de "ser cristiano". Fue un nuevo bautismo. ${ }^{4}$

A todo ello, pienso yo, llevaron los impulsos reales, no solo noticiados, de Juan XXIII, el concilio, Medellín, Gustavo Gutiérrez, la teología de la liberación.

Lo que acabo de decir es personal, pero no creo que sea una experiencia aislada, sino suficientemente generalizada, y por eso la he mencionado. Y según haya sido esa experiencia, así será la celebración hoy, 30, 40 o 50 años después. De esa forma, quizás no sea tan fácil encontrar el modo adecuado de celebrar hoy, pero sí se podrá sentir mejor la necesidad de agradecer algo importante. Y eso lleva a la celebración, pues el agradecimiento no puede permanecer eternamente mudo.

De los acontecimientos que recordamos estos días me parece importante celebrar que fueron rupturas hondas y humanizadoras en la historia del continente, y todavía mayores en la historia de la Iglesia. Pensando en el concilio, podemos celebrar que "ocurrió lo que no se pensaba posible que ocurriese": ventanas abiertas, aire fresco, creyentes más cristianos cuanto más insertos en el mundo, pues son del mundo - mundanales, que no mundanos-, Iglesia del

4. J. Sobrino, "Ser cristiano hoy", Concilium 340 (2011), pp. 191 y s. 
consolamini a pueblos afligidos, no Iglesia del anatema y del fuego del infierno, Iglesia que piensa y anima a pensar las cosas de esta tierra, y que aprende de lo que se piensa en la tierra. Y que piensa también las de Dios, pero sin creerse que de esas cosas, en definitiva, ella tiene el monopolio absoluto. El concilio hizo respirar. Y eso podemos celebrar.

Pensando en Medellín, Gustavo Gutiérrez, y después en monseñor Romero, Puebla, podemos celebrar que la Iglesia se volcó al pobre. Dio ultimidad a la justicia y a la esperanza de "que el rico no aplastará al pobre, ni el verdugo triunfará sobre la víctima”. Y podemos celebrar que el pobre acogió a la Iglesia.

Podemos celebrar que la Iglesia volvió a Jesús. Y de hecho en los acontecimientos mencionados, de una u otra forma asomaba el Dios de Jesús.

Eso produjo ya entonces, la ilusión y la esperanza de que, dicho en su máxima generalidad, "otro cielo y otra tierra son posibles". Y pienso que entonces se hubiese hablado así basados más en la realidad y menos en un voluntarismo utópico organizado.

De lo concreto que hoy podemos celebrar solo me voy a fijar en tres cosas que, tal como lo veo, han ocurrido en el pensar teológico. Para mí, fueron revoluciones reales y pienso que siguen siendo necesarias.

(1) En el Vaticano II se aceptó la Ilustración clásica, y ello trajo muchos bienes. En palabras de Kant, se exigía a los creyentes, también cuando buscábamos comprender a Dios y comprender nuestra fe, tener el coraje de pensar por uno mismo y "despertar del sueño dogmático". Una cosa es la docta ignorancia, la teología apophatica, y otra "estar dormidos en sueños".

En Medellín se exigió otro despertar: "Despertar del sueño de cruel inhumanidad". Es la exigencia de Montesinos en su discurso de 1511 ante los encomenderos. Estos maltrataban y privaban de vida a los indios. Montesinos los conminó, los desnudó de su ignorancia y desenmascaró su ceguera con estas palabras: “Cómo estáis en sueño tan letárgico dormidos?”.

Hoy podemos y debemos celebrar el despertar de ambos sueños, ciertamente "el sueño de siglos de cruel inhumanidad". Ese despertar está en el fondo del cambio eclesial y de la fe. Se expresa en ver la realidad con lucidez, en la decisión de trabajar por los pobres y su liberación, en echar la suerte con ellos. Celebramos, entonces - tras siglos de ignorar la exigencia-, el despertar a una mayor verdad, a un mayor amor. Junto a ello celebramos la difícil conversión en contra de lo viejo endurecido y en favor de lo nuevo, en liturgias, catequesis, música popular, poesía, nuevas teologías...

(2) En varios sectores de la teología de la liberación, emergió la dialéctica no solo en el proceso de pensar, sino en el contenido de lo pensado. Y en cosas fundamentales. "Dios de vida e ídolos de muerte", "reino y antirreino". Esto 
significó también usar la negación para conocer sub specie contrarii lo positivo de Dios, de la gracia, de la práctica de la justicia. A nivel práxico y pastoral, ayudó a adoptar la dirección correcta de lo que hay que hacer. Hay que luchar a favor de la justicia; y cuando eso parece difícil de determinar, al menos hay que luchar contra la injusticia ${ }^{5}$. Ayudó a pensar a Dios como el Dios mayor y el Dios menor. Y con gratuidad ayudó a pensar en Dios como realidad que posibilita todo en contra de la nada que lo engulle todo.

(3) Y surgió un pensar parcial, que emergía desde los pobres y se orientaba hacia los pobres. Pienso que fue una forma eficaz de retomar lo esencial de la Escritura en sentido estricto. En el Antiguo Testamento, la verdadera confessio Dei es "en Ti el huérfano encuentra compasión". En el Nuevo Testamento, Jesús "anuncia el Reino de Dios únicamente a los pobres" ". Esa parcialidad no elimina el aliento universal de Dios para que todas sus criaturas tengan vida. Pero expresa de manera inocultable e inmanipulable la compasión de Dios hacia lo devastado de su creación.

En conclusión, hay mucho que celebrar. Sobre todo, la entrega de la vida con amor, de centenares y miles de cristianos, obispos y sacerdotes, laicos y religiosas, campesinos y estudiantes. En vida y en muerte, se parecieron a Jesús y lo hicieron presente. Recordemos, para concluir, el poema de Pedro Casaldáliga: "San Romero de América, pastor y mártir nuestro". Y la sentencia de Ellacuría: "Con monseñor Romero, Dios pasó por El Salvador". Y ha habido muchos monseñores Romero, ellas y ellos, desconocidos y pequeños. Muy reales.

\subsection{Qué hacer con el pasado: "Volver a fuentes de aguas vivas"}

La finalidad de este congreso es abordar nuevos desafíos, preguntarse por las futuras tareas desde un nuevo contexto. Esto no es fácil, y en un reciente artículo Pedro Trigo explica cuán profunda es la dificultad. No es fácil hacer justicia a la nueva época a la que nos estamos abriendo. $Y$ entre las razones que da, mencionamos la que ahora nos interesa recalcar: "La inercia que lleva a permanecer en lo que se vivió, máxime si tuvo relevancia, aunque fuera a un alto precio"8.

5. Entre los jesuitas de Centroamérica, mucho ayudó esa reflexión cuando la Congregación General XXXII, de 1975, afirmó en su decreto sobre la identidad del jesuita que la misión de la Compañía de Jesús es "la lucha crucial de nuestro tiempo: la lucha por la fe y la lucha por la justicia que la misma fe exige" (Decreto 2, 2). Si alguien, con mayor o menor buena voluntad, no acababa de comprender qué era la justicia, Ellacuría le preguntaba si sabía qué era la injusticia. Entonces, que comenzara luchando contra ella.

6. H. Wolf, Dodekapropheten I, p. 304.

7. J. Jeremias, Teología del Nuevo Testamento I, p. 142, subrayado en el autor.

8. P. Trigo, "La teología latinoamericana ante los retos epocales", Revista Latinoamericana de Teología 86 (2012), p. 122. 
En el congreso se reflexionará sobre lo que ha cambiado y no ha cambiado en todo el continente, y cuán fácil o difícil es abordar teológicamente las novedades. Desde El Salvador, solo quisiera hacer dos breves observaciones.

(1) Después de 20 años de haber finalizado una guerra formal, la sociedad sigue configurada por homicidios, extorsiones, migraciones forzosas, falta de liderazgos políticos y eclesiásticos. Y no hay visos de reversión, es decir, de novedad significativa. Hay novedades de todo tipo, pero permanecen "triunfantes" dolorosas realidades del pasado.

(2) Desde la muerte de monseñor Romero sí ha cambiado considerablemente, como era de esperar $-\mathrm{y}$ también en el continente, después de Puebla-. Las iglesias se han ido deslizando por una pendiente que las aleja de Medellín. Aparecida fue un intento de revertir ese deslizamiento. Lo consiguió hasta cierto punto, y con avances positivos, pero no lo ha podido revertir.

Hay cosas nuevas y buenas en la Iglesia, pero ya no es lo de antes. Ha disminuido notablemente la honradez institucional para insertarse en la realidad social, la denuncia de los horrores en contra de los pobres, la utopía por la que trabajar y luchar, las cartas pastorales que recordaban la profecía de Bartolomé de las Casas y la ciencia de Vitoria, las homilías proféticas de sacerdotes, que recordaban a Montesinos, las teologías audaces sin caer en ambigüedades que favorecen a los poderosos... Antes había presencia de un Dios más latinoamericano, por compasivo, justo y empequeñecido, por esperanzador, liberador y crucificado. Y las teologías devolvieron a un Jesús que había estado oculto, cuando no secuestrado. Y de esa forma, por fidelidad a Jesús, las Iglesias se ocuparon no solo de la realidad eclesial, sino de la social. Ahora esto no queda claro. Su modo de ser y estar casi siempre acerca a la Iglesia a la derecha.

Es muy cierto. Hay que mirar hacia adelante y transitar los caminos nuevos de la mujer, los indígenas, las religiones, la hermana tierra, la utopía de que muchas cosas son "posibles". Pero no basta con mirar hacia adelante. Y aunque el lenguaje no sea hoy habitual, y pueda sonar políticamente incorrecto, también hay que mirar atrás. Voy a explicarme.

En palabras de Jeremías, Dios se quejaba del olvido de su pueblo, y lo formulaba de manera precisa. "Me abandonaron a mí, fuente de agua viva, y se cavaron pozos agrietados que no conservan el agua" $(2,13)$. Hoy, esto significa al menos no desdeñar mirar al pasado, aunque se haga desde una perspectiva específica del presente. Pero en lo que quiero insistir es en "la búsqueda de aguas vivas". Donde se hallen. En el pasado las hubo. En el presente, pienso que no se encuentran con tanta facilidad y con tal pureza de cristianismo. En el futuro, Dios dirá.

Hoy también es necesario mirar al pasado, y hacerlo con esmero cuando la oscuridad y la impotencia son grandes. Hay pasados que fueron fuentes de aguas vivas, y lo pueden seguir siendo. En épocas de aridez son útiles. En cualquier 
caso, los cristianos debemos tomar en serio nuestro pasado principal, sin que nada lo trivialice. Es la vida de Jesús y su Pascua, cruz y Resurrección. No hay que olvidarla. Y siempre hay que volver a ella.

\section{La Iglesia de los pobres}

En esta segunda parte de la ponencia voy a abordar brevemente solo un tema sistemático: "La Iglesia de los pobres"'. En mi opinión, el tema es de gran importancia para la teología y para la fe, para la Iglesia y para el mundo. Una Iglesia así, en el pasado reciente, fue verdadero sacramento de Jesús y humanizó al mundo. Por su naturaleza, es "fuente de aguas vivas". Sin embargo, no deja de sorprender que hoy apenas se le toma en serio, prácticamente ni siquiera se le menciona.

\subsection{La ilusión de Juan XXIII, el silencio del aula conciliar y "el pacto de las catacumbas"}

Antes del concilio, ya existían movimientos que apuntaban en la dirección de la Iglesia de los pobres: los sacerdotes obreros en Francia, con el apoyo del cardenal Suhard, voces del Tercer Mundo, como la de don Hélder Câmara en Brasil, la de monseñor Georges Mercier de los misioneros de África...

Juan XXIII, en un radiomensaje del 11 de septiembre de 1962, un mes antes de la apertura del concilio el 11 de octubre, dijo con solemnidad: "Hoy la Iglesia es especialmente la Iglesia de los pobres".

Comenzado el concilio, varios obispos pensaban a la Iglesia en esa dirección. El cardenal Gerlier, arzobispo de Lyon, el 26 de octubre de 1962, en una reunión en el colegio belga, habló del deber de la Iglesia de adaptarse con la mayor sensibilidad posible al sufrimiento de los pobres. Y refiriéndose al concilio, dijo: "Si no examinamos y estudiamos esto, todo lo demás corre el riesgo de no servir para nada". Y retomó las palabras de Juan XXIII.

Sin embargo, el 6 de diciembre, dos meses después de la apertura, el cardenal Lercaro habló en el aula conciliar con cierto patetismo. Han sido "dos meses de fatigas y de búsqueda verdaderamente generosa, humilde y fraterna... [Pero] todos sentimos que al concilio le ha faltado hasta ahora algo". Se refería a la Iglesia de los pobres. En el aula conciliar, los padres se desentendieron del tema. Y ese olvido persiste en buena medida hasta el día de hoy.

9. Sobre el tema, he escrito "La Iglesia de los pobres desde el recuerdo de monseñor Romero", Revista Latinoamericana de Teología 86 (2012), pp. 135-155; “"La Iglesia de los pobres' no prosperó en el Vaticano II. Promovida en Medellín, historizó elementos esenciales en el concilio", Concilium 346 (2012), pp. 91-101. 
Varios obispos captaron pronto que a la mayoría le era lejana una Iglesia volcada a los pobres, y decidieron reunirse confidencialmente, con regularidad y sin sectarismo, en Domus Mariae en las afueras de Roma. Pensaron a fondo "la pobreza de la Iglesia", y pocos días antes de la clausura del concilio un buen grupo de padres conciliares celebraron una eucaristía en las catacumbas de Santa Domitila.

Pidieron "ser fieles al espíritu de Jesús", y al terminar la celebración firmaron lo que es conocido como el pacto de las catacumbas. El pacto era un desafío a los "hermanos en el episcopado" a llevar una "vida de pobreza" y a ser una Iglesia "servidora y pobre". Así comienza el texto:

Nosotros, obispos, reunidos en el Concilio Vaticano II, conscientes de las deficiencias de nuestra vida de pobreza según el Evangelio; motivados los unos por los otros en una iniciativa en la que cada uno de nosotros ha evitado el sobresalir y la presunción [...] con humildad y con conciencia de nuestra flaqueza, pero también con toda la determinación y toda la fuerza que Dios nos quiere dar como gracia suya, nos comprometemos a lo que sigue.

Los signatarios se comprometían en 13 puntos a vivir en pobreza, rechazar los privilegios y símbolos de poder y poner a los pobres en el centro de su ministerio.

En conclusión, al interior del aula conciliar se habló sobre los pobres, aunque comedidamente; pero sobre la Iglesia de los pobres se guardó silencio. Se aprobaron dos magníficos textos en los que se menciona a los pobres y, explícita o implícitamente, a la Iglesia. "La Iglesia reconoce en los pobres y en los que sufren la imagen de su fundador pobre y paciente, se esfuerza en remediar sus necesidades y procura servir en ellos a Cristo" ( $L G$ 8). "Los gozos y las esperanzas, las tristezas y las angustias... sobre todo de los pobres y de cuantos sufren, son gozos y esperanzas, tristezas y angustias de los discípulos de Cristo" $(G S 1)^{10}$. Estas palabras dicen cosas importantes sobre la misión de la Iglesia y su espiritualidad, pero no tocan su ser pobre, ni su destino de persecución por defender a los pobres, ni que de los pobres pudiera venirle salvación.

\subsection{Medellín: Iglesia liberadora de los pobres; en sí misma, pobre y perseguida}

En el documento Pobreza de la Iglesia, Medellín recoge el pathos y el ethos del pacto de las catacumbas. Los obispos constatan con honradez las quejas de los pobres "de que la Jerarquía, el clero, los religiosos, son ricos y aliados de los ricos" (n. 2). Y aunque admiten que puede haber alguna exageración, reconocen

10. En el decreto Ad Gentes, se dice que "la Iglesia debe caminar (...) por el mismo camino que Cristo siguió, es decir, por el camino de la pobreza" (n. 5). 
que varias cosas han contribuido a crear la imagen de una Iglesia institucional rica: los grandes edificios, las casas de párrocos y religiosos, cuando son superiores a las del barrio en que viven; los vehículos propios, a veces lujosos; la manera de vestir heredada de otras épocas. "En el contexto de pobreza y aun miseria en que vive la gran mayoría del pueblo latinoamericano, los obispos, sacerdotes y religiosos tenemos lo necesario para la vida y una cierta seguridad, mientras los pobres carecen de lo indispensable y se debaten entre la angustia y la incertidumbre" (n. 3). Y añaden que los pobres no solo se quejan de diferencias materiales, sino de distanciamiento e insolidaridad.

En la conclusión, los obispos se exigen a sí mismos el "testimonio" en el modo de vida y en la administración de los bienes (nn. 12-17), y el distanciamiento del prestigio, la riqueza: "Queremos que nuestra Iglesia latinoamericana esté libre de ataduras temporales, de connivencia y de prestigio ambiguo; que 'libre de espíritu respecto a los vínculos de la riqueza' sea más transparente y fuerte su misión de servicio" (n. 18). Estas declaraciones fungen como principios ad intra de la Iglesia de los pobres.

Y por lo que toca a la misión, los pobres exigen a la Iglesia "la denuncia de la carencia injusta de los bienes de este mundo y el pecado que la engendra". Funge como principio ad extra de la Iglesia de los pobres, lo que en Medellín fue desarrollado ampliamente en el documento Justicia. Comienza con esta afirmación sobre la que se construirá el edificio: "Existen muchos estudios sobre la situación del hombre latinoamericano. En todos ellos se describe la miseria que margina a grandes grupos humanos. Esa miseria, como hecho colectivo, es una injusticia que clama al cielo" (n. 1).

Añaden que ese clamor debe ser oído por los obispos: "Un sordo clamor brota de millones de hombres, pidiendo a sus pastores una liberación que no les llega de ninguna parte" (n. 2). Y sacan las consecuencias: "El episcopado latinoamericano no puede quedar indiferente ante las tremendas injusticias sociales existentes en América Latina, que mantienen a la mayoría de nuestros pueblos en una dolorosa pobreza cercana en muchísimos casos a la inhumana miseria" (n. 1).

Aunque en lenguaje distinto, los obispos recuerdan las palabras del fraile dominico Antonio Montesinos en 1511. La realidad es cruel y el pecado de los encomenderos inmenso. "¿Cómo los tenéis tan opresos y fatigados, sin darles de comer ni curarlos en sus enfermedades, que de los excesivos trabajos que les dais incurren y se os mueren, y por mejor decir, los matáis, por sacar y adquirir oro cada día?". Los encomenderos viven en total deshumanización: “¿Cómo estáis en sueño tan letárgico dormidos?". En Medellín, la Iglesia tuvo el coraje de "despertar del sueño de cruel inhumanidad", denunció la realidad oprimida y se comprometió con su liberación. 
Y ocurrió una de las mayores novedades vistas en la Iglesia latinoamericana: la persecución por causa de la justicia. Trabajar por la liberación del pobre tuvo desde el principio en su contra a los poderes económicos, militares, policiales y en buena parte también mediáticos del continente. Recuérdese el informe Rockefeller en 1968, el documento de la reunión de Santa Fe en 1980, las reuniones de militares en el Cono Sur en la década de los ochenta. Organizaron campañas crueles, a las que a veces se unió parte de la Iglesia institucional.

La persecución desembocó en el martirio. Fue lo más jesuánico que ocurrió: vivir, hacer y ser dados muerte como Jesús de Nazaret. Persecución y martirio se convirtieron en un existencial histórico de la Iglesia de los pobres.

Esta persecución asustó a la institución eclesial, que además vio con temor cómo Medellín y varios prominentes obispos - más la teología de la liberación- concedían adultez y libertad a los cristianos que se comprometían con los pobres. Sentía que se tambaleaba el poder de la jerarquía. Y vino la reacción. Varios obispos fueron maltratados, y la teología de la liberación fue combatida.

\subsection{El Salvador: Iglesia de los pobres, perseguida, crucificada}

Esta Iglesia se hizo realidad en varios lugares de América Latina. Y en notable medida en El Salvador. Ignacio Ellacuría hizo un importante avance teórico, con serias consecuencias prácticas, al precisar conceptualmente qué hay que entender por "Iglesia de los pobres". Sobre ello escribió tres textos ${ }^{11}$, de los que citamos lo fundamental.

La Iglesia de los pobres no significa una parte de la Iglesia, enfoque regional, sino una nota constitutiva y configurativa de toda la Iglesia. Hace la opción preferencial por los pobres y con las consecuencias que esta opción produce, tanto para la constitución jerárquica y organizativa de la Iglesia institucional como para lo que ha de ser su evangelización. Es una Iglesia solidaria y preferencialmente solidaria con la causa de los pobres. Y por esa razón es una Iglesia perseguida, y perseguida precisamente por los ricos. Cuando los pobres ocupan el lugar que les corresponde en la Iglesia, entonces la institución eclesial es una institución con espíritu. Y las bienaventuranzas pueden considerarse la carta fundacional de la Iglesia de los pobres.

Profundicemos brevemente en cuatro puntos. (1) El fundamento último de la Iglesia de los pobres, como de toda realidad teológica, es teologal. "La unión de

11. I. Ellacuría, "La Iglesia de los pobres, sacramento histórico de liberación”, ECA (noviembre-diciembre 1977), pp. 707-722; "Pobres", en C. Floristán y J. J. Tamayo, Conceptos fundamentales de pastoral, Madrid, 1983, pp. 798-801; "Las bienaventuranzas, carta fundacional de la Iglesia de los pobres", en Escritos teológicos II, 2000, pp. 417-437, publicado originalmente en 1979. 
Dios con los hombres, tal como se da en Jesucristo, es históricamente una unión de un Dios vaciado en su versión primaria al mundo de los pobres" ${ }^{\prime 2}$. (2) La Iglesia de los pobres "no es aquella que, estando fuera del mundo de los pobres, le ofrece generosamente su ayuda" ${ }^{13}$. Es decir, la Iglesia no queda constituida con independencia lógica de los pobres para preguntarse - después-, una vez constituida, qué debe hacer por ellos. (3) Los pobres posibilitan y propician la identidad salvífica de la Iglesia. "Encarnándose entre los pobres, dedicando últimamente su vida a ellos y muriendo por ellos, es el modo como puede constituirse cristianamente en signo eficaz de salvación de todos los hombres"14. (4) Los pobres configuran a la Iglesia desde dentro, lo cual ha sido y es prácticamente ignorado. "Los pobres son su principal sujeto y su principio de estructuración interna" ${ }^{15}$. Esto significa que los pobres son - juntamente con el Evangelio y con la tradición genuinamente evangélica- el principio configurador del seguimiento, la espiritualidad, la doctrina, la liturgia, la moral, el derecho canónico, la formación en seminarios y conventos...

La Iglesia perseguida. Los pobres ponen a la Iglesia, por su naturaleza y sin escapatoria, ante el Evangelio. Y cuando, además de ayudarlos, sale en su defensa, entonces ex opere operato la Iglesia queda enfrentada con los ídolos, divinidades de muerte. Se convierte en una Iglesia perseguida por necesidad, superando lo que en el concilio se afirma solo genéricamente: "La Iglesia va peregrinando entre las persecuciones del mundo y los consuelos de Dios" ( $L G 8)$.

Monseñor Romero vivió y comprendió así a la Iglesia. Y dijo que esa, y no otra, era la verdadera Iglesia. En un arrebato evangélico, declaró la persecución como bienaventuranza. "Me alegro, hermanos, de que nuestra Iglesia sea perseguida, precisamente por su opción preferencial por los pobres y por tratar de encarnarse en el interés de los pobres" (Homilía del 15 de julio de 1979).

La Iglesia martirizada. Y en otro arrebato evangélico, dijo: "Sería triste que en una patria donde se está asesinando tan horrorosamente no contáramos entre las víctimas también a los sacerdotes. Son el testimonio de una Iglesia encarnada en los problemas del pueblo" (Homilía del 24 de junio de 1979). La Iglesia de los pobres es la Iglesia también perseguida y crucificada.

Al hablar de Iglesia, hay que recordar que tanto monseñor Romero como el padre Ellacuría compartían la importancia que el concepto "pueblo" tiene en la eclesiología del Vaticano II. Y dada la situación de El Salvador, lo historizaron como pueblo crucificado. Ellacuría insistió en su dimensión salvífica, y en 1978 escribió "El pueblo crucificado. Ensayo de soteriología histórica". Y en

12. I. Ellacuría, "La Iglesia de los pobres, sacramento histórico de liberación”, op. cit., p. 717.

13. Ibidem.

14. Ibidem.

15. Ibidem. 
1981, proclamó audazmente: "El pueblo crucificado es siempre el signo de los tiempos". Poco antes que Ellacuría, monseñor Romero había tenido la misma intuición. El 19 de junio de 1977, en Aguilares, tras un mes de asesinatos de campesinos, equiparó al pueblo sufriente con Cristo crucificado: "Ustedes son la imagen del Divino Traspasado... [Este pueblo] es la imagen de todos los pueblos que, como Aguilares, serán atravesados, serán ultrajados".

Así han sido las Iglesias como la de monseñor Romero, de don Samuel Ruiz, de Leonidas Proaño... La de don Pedro Casaldáliga, en nuestros días.

El concilio nada dijo de una Iglesia perseguida y menos de una Iglesia crucificada por causa de la justicia. Los tiempos no estaban para hacer a pobres y cruces reales - junto con su Señor-, lo central de la Iglesia. Sí abrió espacios para hablar de esta forma, pero de los pobres solo habló en forma comedida. Y fue triste, ahora sin responsabilidad del concilio, que con la marcha atrás de la jerarquía vaticana y de otras locales, se quiso denostar a la "Iglesia de los pobres", llamándola, estudiadamente, "Iglesia popular".

A mi entender, tampoco en muchas de las teologías actuales la Iglesia de los pobres es un tema muy tratado. Y el pacto de las catacumbas es desconocido. Más se habla en ellas - y se añora- de la Iglesia pueblo de Dios, aunque tampoco se le relacione con los pueblos crucificados.

$$
* * *
$$

En la Iglesia de los pobres están los pobres que traen salvación. En palabras sencillas, así lo dijo monseñor Romero: "Con este pueblo, no cuesta ser buen pastor".

Y en esa Iglesia está la fe de los pobres. El día que cumplía 80 años le oí decir a José Comblin: "Para mí, la fe es lo más fácil que hay. La veo en los campesinos con quienes vivo".

Me recuerdan la ilusión que tenía el Papa Bueno: "La Iglesia es especialmente la Iglesia de los pobres". 